\title{
HEPATITE B: A MICROSCOPIA ELECTRÓNICA NA PATOLOGIA E ETIOPATOGENIA DA DOENÇA HEPÁTICA AGUDA E CRÓNICA
}

\author{
Jorge de Oliveira Soares
}

Cadeira de Bacteriologia e Virologia do Instituto de Higiene e Medicina Tropical, Lisboa. Unidade de Microscopia Electrónica, Faculdade de Medicina de Lisboa.

\section{RESUMO}

No presente trabalho destaca-se o contributo da microscopia electrónica de transinissão para o esclarecimento de aspectos fundamentais da patologia, patogenia e etiologia da hepatite B. São mencionadas as alteraçōes principais dos organelos dos hepatocitos no decurso da hepatite aguda e das formas crónicas da doença, e a sua relaçăo com as perturbaçōes da função hepática. São referidos os caracteres morfológicos dos componentes antigénicos do vírus da hepatite B ( $\mathrm{AgHBs}$ e $\mathrm{AgHBc}$ ), a sua localização intra-hepatocitária e a sua ocorrência nas diferentes formas de doença hepática com antigenémia HBs. E discutida a patogénese celular das alteraçōes hepáticas na hepatite aguda e sugere-se a possibilidade de as relaçōes intercelulares entre linfocitos e hepatocitos corresponderem à expressão morfológica de mecanismo imunológico contributivo para a evolução crónica da doença.

A microscopia electrónica tem sido aplicada ao estudo das hepatites, quer para o conhecimento das alteraçōes subcelulares que ocorrem no decurso da doença, quer para a identificação de partículas e estruturas relacionáveis com vírus.

No presente trabalho, pretendem abordar-se alguns dos aspectos principais do conhecimento actual da hepatite $\mathrm{B}$, obtidos com o emprego de técnicas de microscopia electrónica de transmissão:

— as alteraçōes ultrastruturais das células parenquimatosas do fígado na hepatite aguda viral, e alguns aspectos relativos a formas crónicas; tocitária;

- as particulas relacionadas com o vírus da hepatite B de localização intra-hepada doença.

- a patogénese celular das alterações hepáticas nas formas agudas e crónicas

As conclusões que se apresentam baseiam-se na revisão da literatura, e no estudo de biópsias hepáticas de doentes com hepatite aguda e hepatite crónica, efectuado na Unidade de Microscopia Electrónica da Faculdade de Medicina de Lisboa, de 1974 a 1977. 


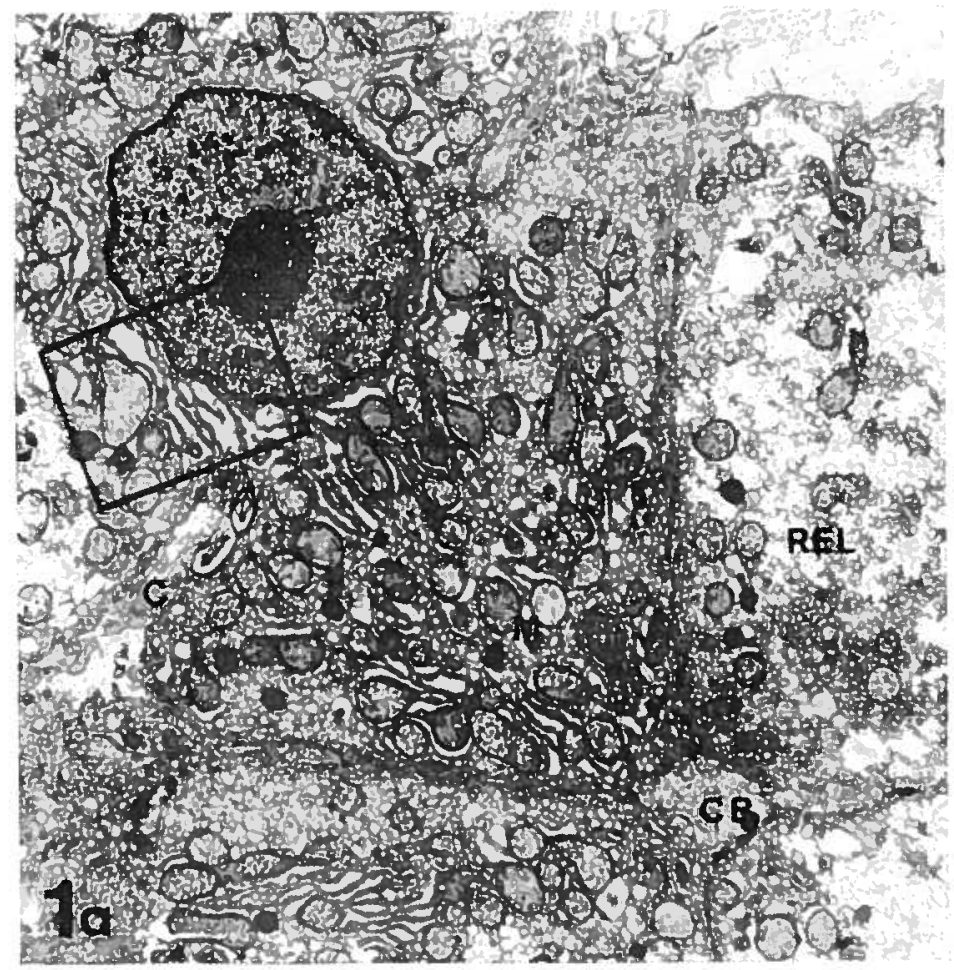

Fig. La Mrcoofotografia onde se obsertam porgozes de + células bepaticas. em um caso de bepatite aguda por virtts. O núcleo está allmentado d. volume. a membrana nuclear; é irregular, o nucléolo é proeminente. $H a$ dilatą̧ão e disrup̧̧āo de cisternas do reticulo endoplasmático rugoso (RER) * diferenças na densidade da matriz das mitocóndrias ( $M)$. Na célula rituada à direita ua figura, observa-se praticamente o desaparecimento do reticulo endoplasmático rugoso e a exuberante proliferaçäo e vesiculação do reticulo liso (REL). Na confluência dos: quatro bepatocitos observa-se "um ranaliculs biliar (CB) moderadamente dilatado. com diminuiça do número de vilosidades. $x 3900$

\section{A ultrastrutura do figado na bepatite $B$}

Os aspectos ultrastruturais do fígado na hepatite aguda por vírus são idênticos aos que se observam em outros processos inflamatórios agudos deste órgão, nomeadamente os produzidos por certas drogas. Tal como acontece na observação ao microscópio de luz também, em microscopia electrónica, nāo há caracteres distintivos, no quadro das alterações hepáticas, entre as hepatites $\mathrm{B}$ e as não $\mathrm{B}$, designadamente as hepatites infecciosas. Existe uma relativa discrepância entre as alterações observadas ao microscópio óptico e as que se observam ao microscópio electrónico, sendo estas relativamente menos importantes que aquelas (Jézéquel e Steiner 1967; Schaffner 1970). A distribuição das lesões é variável, havendo zonas de marcadas alterações celulares, 


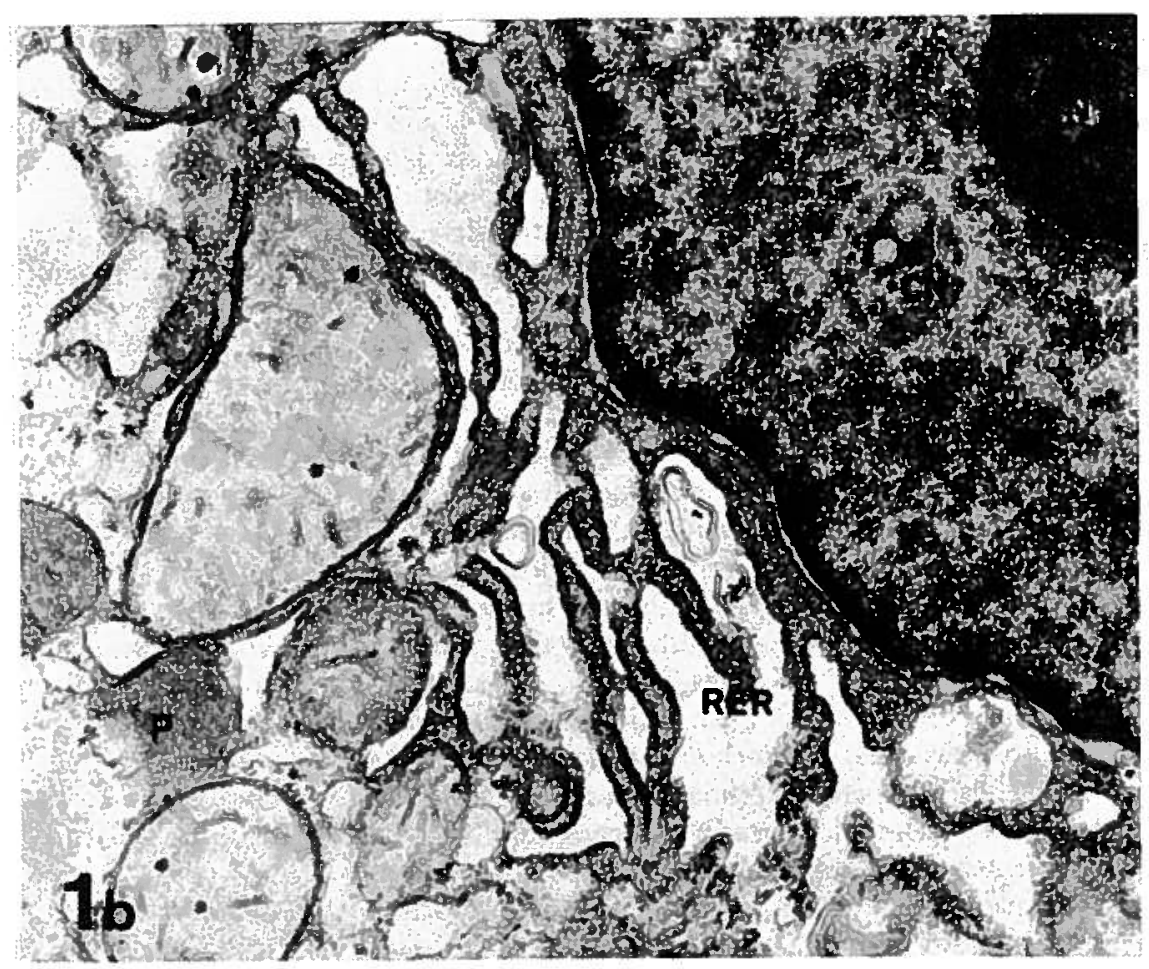

Fig. 1b-Ampliạ̧ão da regiāo marcada na fig. 1a. Observa-se no núcleo um corpo nuclear de tipo IV. (Bouteille). $\times 23150$

vizinhas de outras com células aparentemente normais, ou com lesões morfologicamente minimas.

No núcleo dos hepatocitos, os achados mais frequentemente observados dizem respeito às alterações do seu volume e da configuração da membrana nuclear, a qual assume, em regra, um aspecto ondulado (figs. la e 1b). Este aspecto, que também ocorre em outras infecções virais, poderá relacionar-se com o aumento das interacçōes núcleo-citoplasmáticas do hepatocito (Marsella 1972; Trump et al. 1976). A hipertrofia do núcleo é, classicamente, indicativa de processo regenerativo celular. Igual significado poderão ter o aumento das dimensões e a duplicação do nucléolo, bem como a presença, em número superior ao normal, de corpos nucleares, com estrutura por vezes muito complexa, a que se atribui, também, uma relaçāo com o processo de replicação do vírus. (Scotto e Stralin 1976; Soares e Moura 1975).

No citoplasma do hepatocito as alteraçōes mais importantes observam-se no retículo endoplasmático. O reticulo rugoso apresenta dilatação e disrupção das cisternas, que ocorrem cedo no curso da doença (fig. 1b). É frequente a perda da relação habitual dos ribosomas com os perfis do retículo endoplasmático. Estas alteraçōes têm sido relacionadas com perturbações intra-hepatocitárias da síntese proteica (Willis 1968; Ruebner e Slusser 1968). O retículo endoplasmático liso apresenta vesiculação, por vezes muito intensa. $\mathrm{O}$ aumento $\mathrm{e}$ a vesiculação do retículo endoplasmático algumas vezes é exube- 
rante, originando grande aumento do volume da célula o que, em microscopia de luz, corresponde ao aspecto de células em baläo.

As alterações das mitocôndrias são pouco marcadas, podendo, contudo, observar-se alterações do volume do organelo ou, ainda, formações cristalinas intramitocondriais.

Existe, em geral, um aumento do número de peroxisomas cujo significado no curso das alterações da doença não está ainda esclarecido (Schaffner 1970).

O complexo de Golgi está frequentemente dilatado, contendo material floculento, alterações estas que se relacionam com as perturbações da secreção biliar. Com frequência, particularmente nas formas ictéricas, observam-se figuras de mielina ou inclusões lamelares (fig. 2), correspondentes a enrolamentos de membranas (fosfolipídicas?), em geral atribuídos aos efeitos da lesão celular subletal (Trump et al. 1976). Os processos de necrose das células hepáticas podem conduzir à lise e condensação das mesmas, que são eliminadas para os espaços vasculares. Apresentam-se, ao microscópio electrónico, como massas mais ou menos volumosas, densas aos electrões (fig. 3), e correspondendo aos corpos acidófilos, achado histológico habitual na hepatite aguda.

O edema e a redução do número das vilosidades do hepatocito, na sua superfície sinusoidal, são uma observação frequente na hepatite aguda (fig. 3). As alterações do pólo biliar da célula hepática, embora, em geral, importantes, parecem ser reversíveis e associam-se com a estase biliat e a icterícia. Essas alterações traduzem-se na dilatação, distorsão e perda das vilosidades, em maior ou menor grau, sendo os canalículos biliares, quando muito ectasiados, completamente desprovidos de vilosidades.

$\mathrm{Na}$ fase da recuperação celular encontram-se, com frequência, células com abundantes lisosomas, sobretudo formando corpos residuais com pigmento de lipofuscina $e$, menos frequentemente, hemossiderina.

$\mathrm{Na}$ sequência do processo regressivo, os hepatocitos tomam um aspecto que, do ponto de vista ultrastrutural, se não distingue do do fígado normal. Feixes de fibras colagénias, em regra escassos, nos espaços de Disse, são indicativos de processo cicatricial residual (fig. 5).

Nas formas que evoluem para a cronicidade, as alteraçōes da célula hepática, dependem da fase clínica em que a biópsia hepática é feita: nas fases de agudização as imagens dos hepatocitos são sobreponíveis às da hepatite aguda (fig. 4); nas fases de doença não activa, os aspectos são sobreponíveis aos das fases de recuperação, mais ou menos próximos dos do fígado normal (Trump et al. 1976). Em todo o caso são frequentemente observadas alterações moderadas que, embora não específicas, se relacionam com o processo subjacente e a actividade da doença. Essas alterações são sobretudo do retículo endoplasmático, quer liso quer rugoso, da forma e volume das mitocôndrias e do número de peroxisomas e lisosomas.

\section{Estruturas intra-bepiticas relacionadas com o virus da bepatite $B$}

Sabe-se que a partícula viral do vírus da hepatite $B$ tem dois componentes: o componente interior $\mathrm{e}$ o de superfície, a que correspondem determinantes antigénicos distintos, respectivamente, $\mathrm{AgHB}_{\mathrm{c}} \mathrm{e} \mathrm{AgHB}_{\mathrm{s}}$. Estes dois componentes são, provavelmente, sintetizados, a nível do fígado, em locais diferentes da célula hepática e têm diferente expressão morfológica ultrastrutural (Jokelainen et al. 1970; Gerber et al. 1972). Assim, formações esféricas, de cerca de $20 \mathrm{~nm}$ de diâmetro, dispersas no seio da cromatina nuclear ou em pequenos agregados de dimensões variáveis correspondem ao componente central da partícula viral $\left(\mathrm{AgHB}_{\mathrm{c}}\right)$ (fig. 6). São muito raramente observadas na fase aguda da doença, sendo mais frequentemente encontradas nas formas 


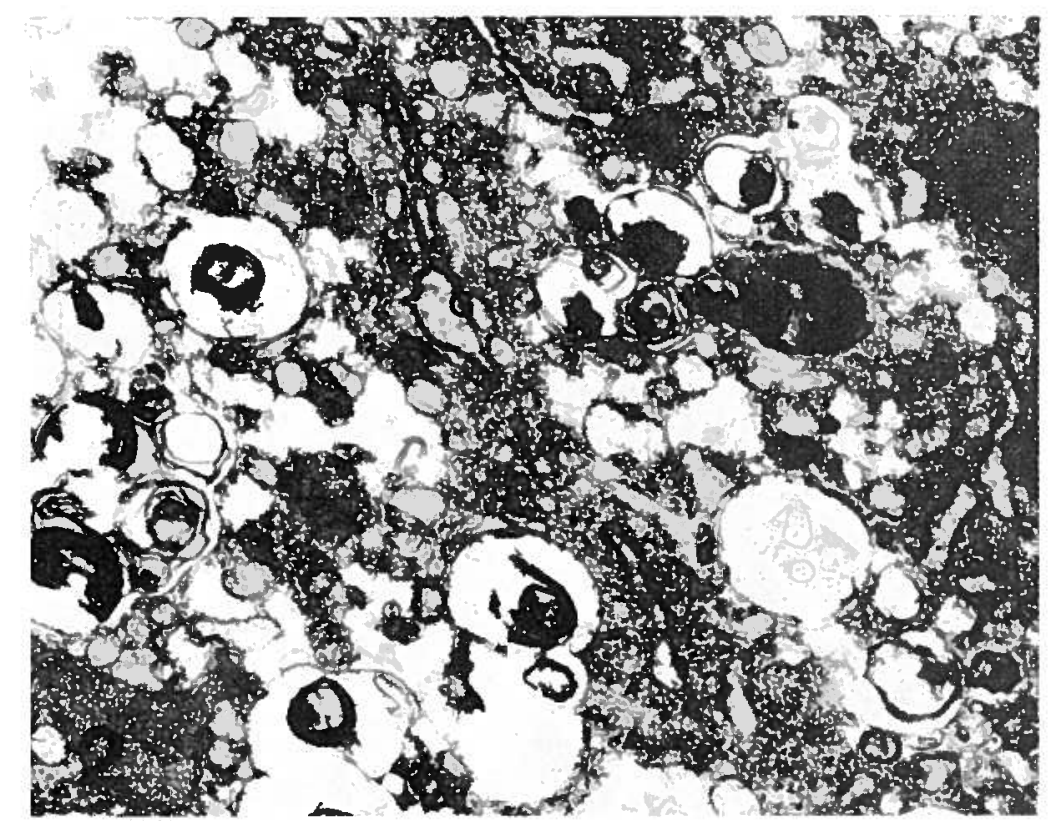

Fig. 2 - Porçăo de um bepatocito de um doente com bepatite aguda e icterícia. Numerosas "figuras de mielina». Porfão de um complexo de Golgi dilatado, com material floculento no interior das vesiculas e cisternas. $x 22100$

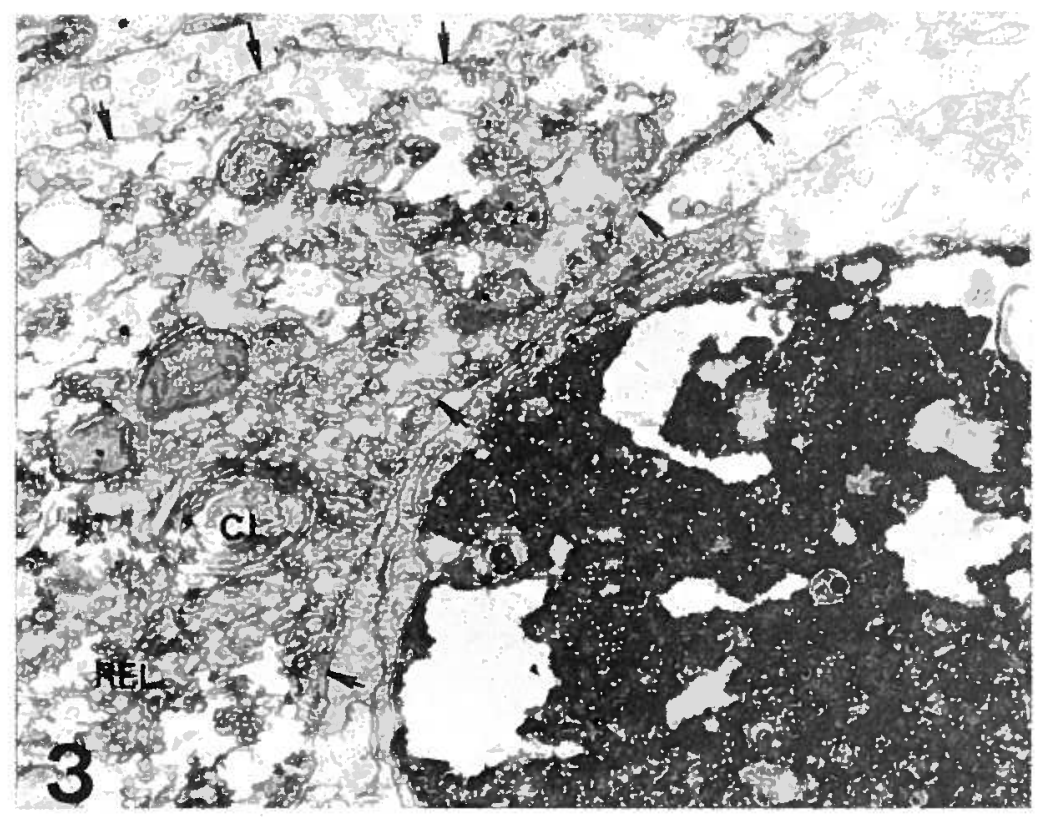

Fig. 3 - Massa osmiofílica contida numa célula macrofagica do sinusóide be tico (corpo acidófilo). A superficie do bepatocito está praticamente despron de vilosidades (setas). Hipertrofia do retículo endoplasmático liso (RE Corpo lamelar (CL). $\times 11600$ 


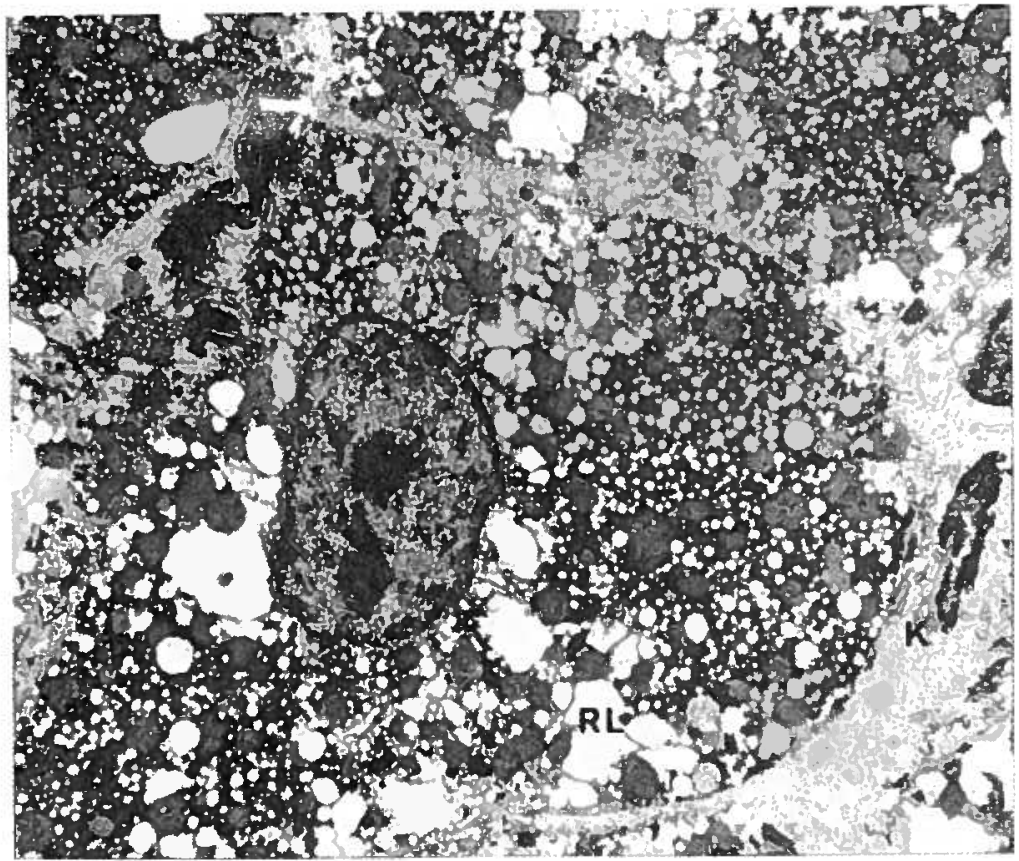

Fig. 4-Intensas lesües celulares nos bepatocitos de um doente com reactivafăo clinica e laboratorial de bepatite crónica agressitia. Marcada dilataf̧ão vesicular do retículo endoplasmático (RL) Feixes de fibras colagénias (C). Célula de Kupffer $(K) . \times 5500$

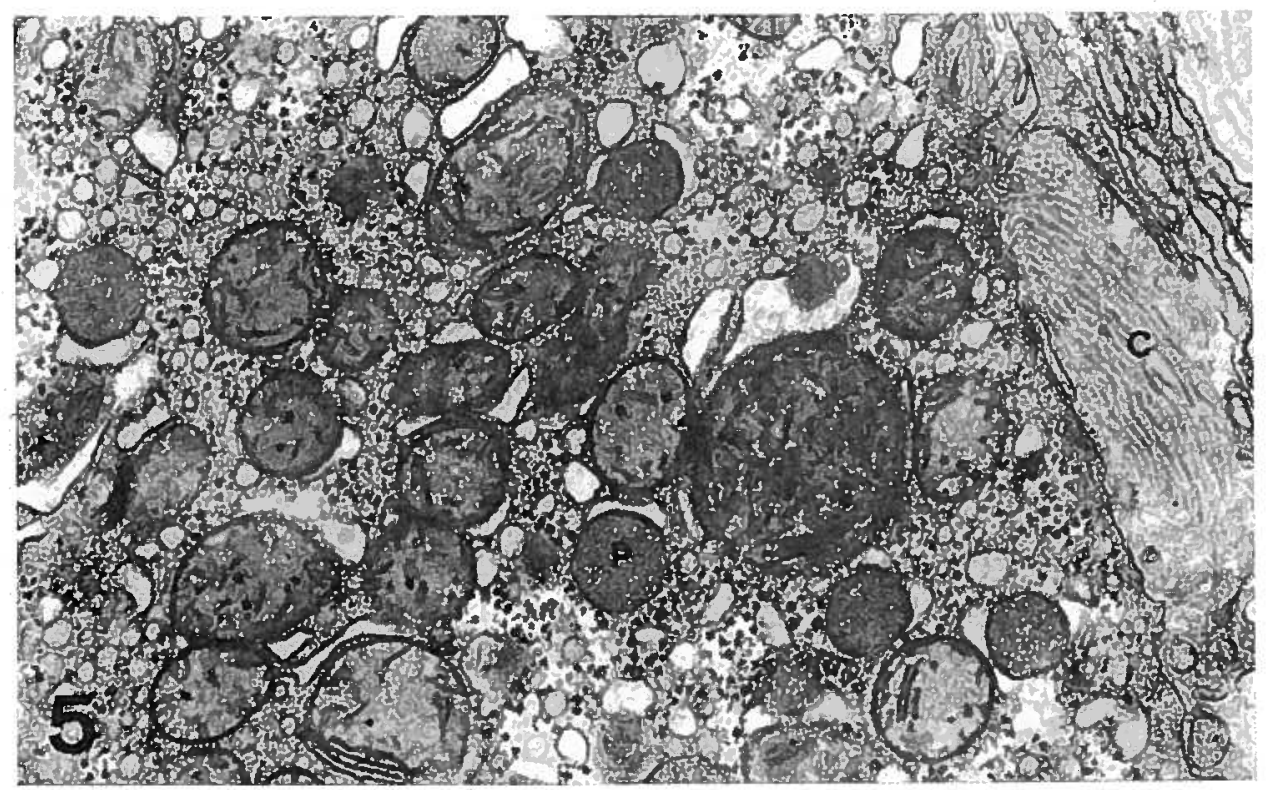

Fig. 5-Pleiomorfismo das mitocôndrias. Cristas milocondriais com perda da sua disposiçäo bubiunal. Aumento do número de peroxisomas (P). Tibras colagénias no espaso de Disse (C). $\times 14500$ 
de doença hepática crónica associadas ao $\mathrm{AgHB}_{\mathrm{s}}$ e, somente, em alguns hepatocitos de portadores assintomáticos (Woolf e Williams 1976).

As partículas que a imunofluorescência e as técnicas de imunomicroscopia electrónica permitiram identificar como relacionadas com o $\mathrm{Ag} \mathrm{HB}_{3}$, localizam-se no citoplasma da célula hepática (Gerber et al. 1975).

Essas particulas têm o aspecto de perfis tubulares e circulares, de comprimento variável e diâmetro de $20-24 \mathrm{~nm}$, e localizam-se no interior das cisternas do retículo endoplasmático, o qual apresenta marcada proliferação. Quando em grande quantidade na célula hepática, esta adquire o aspecto descrito em microscopia óptica por ground-glass, tomando essas células coloração positiva pela orceina. Estes perfis tubulares devem representar a camada exterior proteica do vírus ou uma reaç̧ão da célula-hospedeiro ao antigénio viral (Almeida e Waterson 1975). As partículas $\mathrm{Ag} \mathrm{HB}$ s estão presentes no citoplasma de menos de $5 \%$ dos hepatocitos na doença hepática crónica (hepatite crónica activa e'cirrose hepática) e, em quase metade dos hepatocitos nos portadores assintomáticos do $\mathrm{Ag} \mathrm{HB}_{\mathrm{s}}$ (Woolf e William 1976).

\section{A patogénese celular das alteraşōes bepáticas na bepatite aguda e crónica}

As observaçöes ao microscópio electrónico de biópsias humanas realizadas em diferentes fases da doença viral permitiram alargar a compreensão das alterações identificadas em microscopia de luz, e da fisiopatologia das estruturas celulares do fígado, nomeadamente dos hepatocitos.

A redução da função hepática na hepatite aguda é, não tanto o resultado da diminuição da massa do tecido hepático funcionante, como, sobretudo, a consequência do funcionamento deficiente da massa das células sobreviventes (Schaff́ner 1970).

A lesão dos organelos atrás descrita e as perturbações da secreção biliar e da circulação sanguínea, pela presença das células inflamatórias intra- e perisinusoidais, são responsáveis pelas perturbações da função hepática.

As alterações intrahepatocitárias observadas no decurso da doença permitiram aventar modelos explicativos dos fenómenos patogénicos que ocorrem na infecção viral aguda do fígado. Assim, segundo Trump (1976), a interacção entre vírus e célula levaria, provavelmente por mecanismo imunológico (mediado por complemento?, anticorpos?), a alterações da membrana celular do hepatocito com comprometimento dos mecanismos de difusão passiva, iónica e aquosa, e, também, dos de transporte activo. A interacção vírus-hepatocito, involvendo primariamente lesão funcional da membrana celular, inicia uma sequência complexa de fenómenos (Quadro I) de que resultaria a característica disfunção hepatocelular desta doença. Os desvios anormais de iōes através da membrana plasmática seriam, de acordo com Trump, predominantemente no sentido da entrada de sódio para a célula e subsequente entrada de água, sem a saída correspondente de outros iões, nomeadamente de potássio. Haveria um aumento de volume da célula, tendo como contrapartida morfológica a dilatação do retículo endoplasmático e o aspecto de balonização celular. Este facto também explicaria a obstrução canalicular parcial e a estase biliar e, portanto, o componente colestático observado em muitas formas de hepatite. O hepatocito dilatado poderia sofrer duas evoluçōes: ou a reparação celular, restitutio ad integrum, com saída de sódio da célula, entrada balanceada de iões potássio e restabelecimento da integridade morfofuncional da membrana da célula hepática, ou a morte celular, por rebentamento.

A condensação da célula hepática, por lise, que em microscopia óptica se traduz na presença de corpos acidófilos, poderia corresponder à saída de potássio da célula 


\section{QUADRO I}

Representaçāo esquemática de fenómenos patogénicos que ocorrem ao nivel da célula bepática na bepatite aguda (Adaptado e simplificado de Trump et al 1976)

Interacçäo virus-hepatocito

(Ac?, C'?)
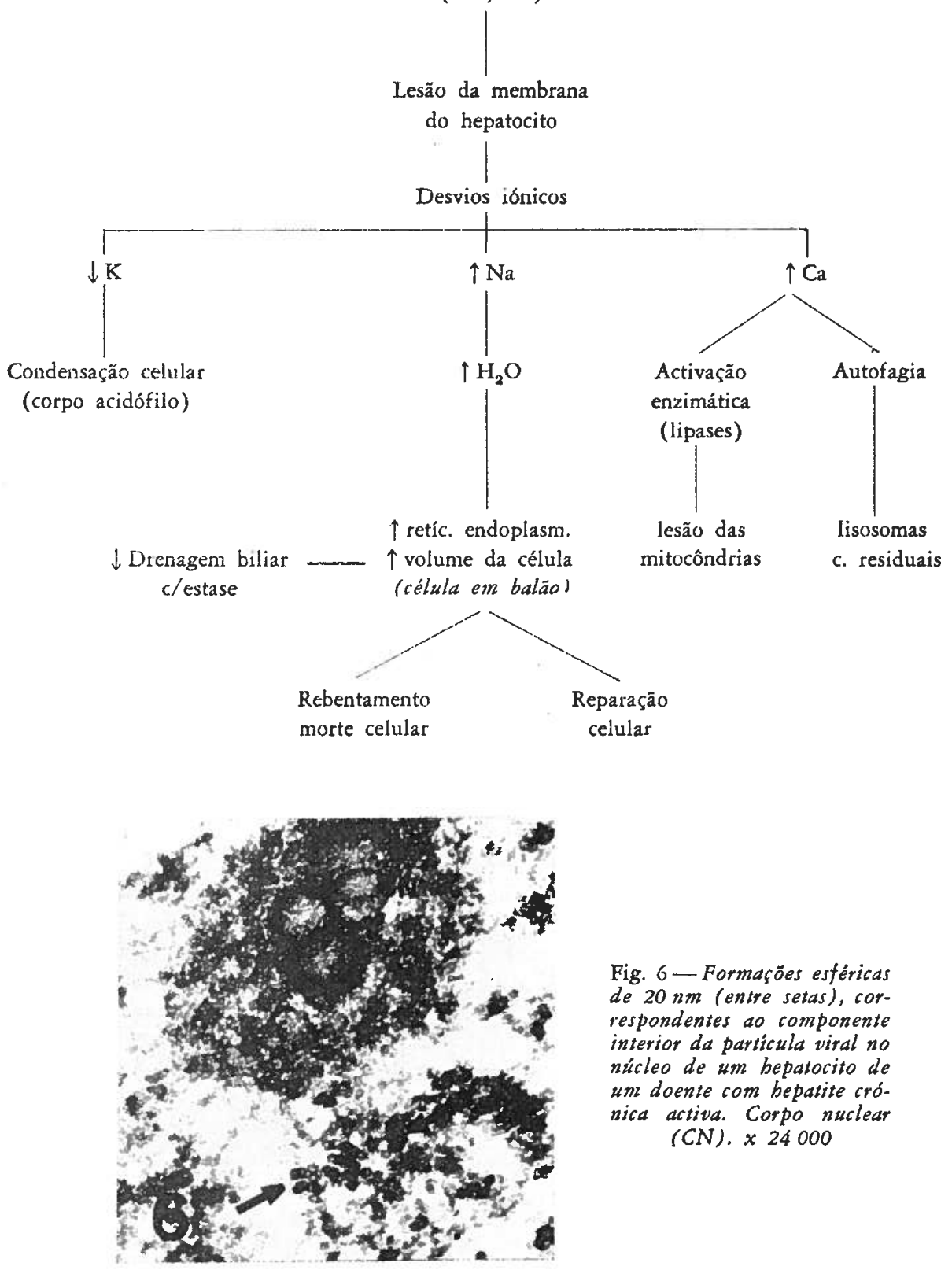

Fig. 6-Formaçöes esféricas de $20 \mathrm{~nm}$ (entre setas), correspondentes do componente interior da particula viral no núcleo de $\mathrm{um}$ bepatocito de um doente com bepatite crónica activa. Corpo nuclear (CN). $\times 24000$ 
Fig. 7 - Hepatite crónica activa. Associasăo de linfocito com uma célula bepática que mostra alteraşöes citoplasmáticas do retículo endoplasmático com marcada dilatafão. Existe contacto de superficie entre as membranas celulares (seta). $\times 8500$
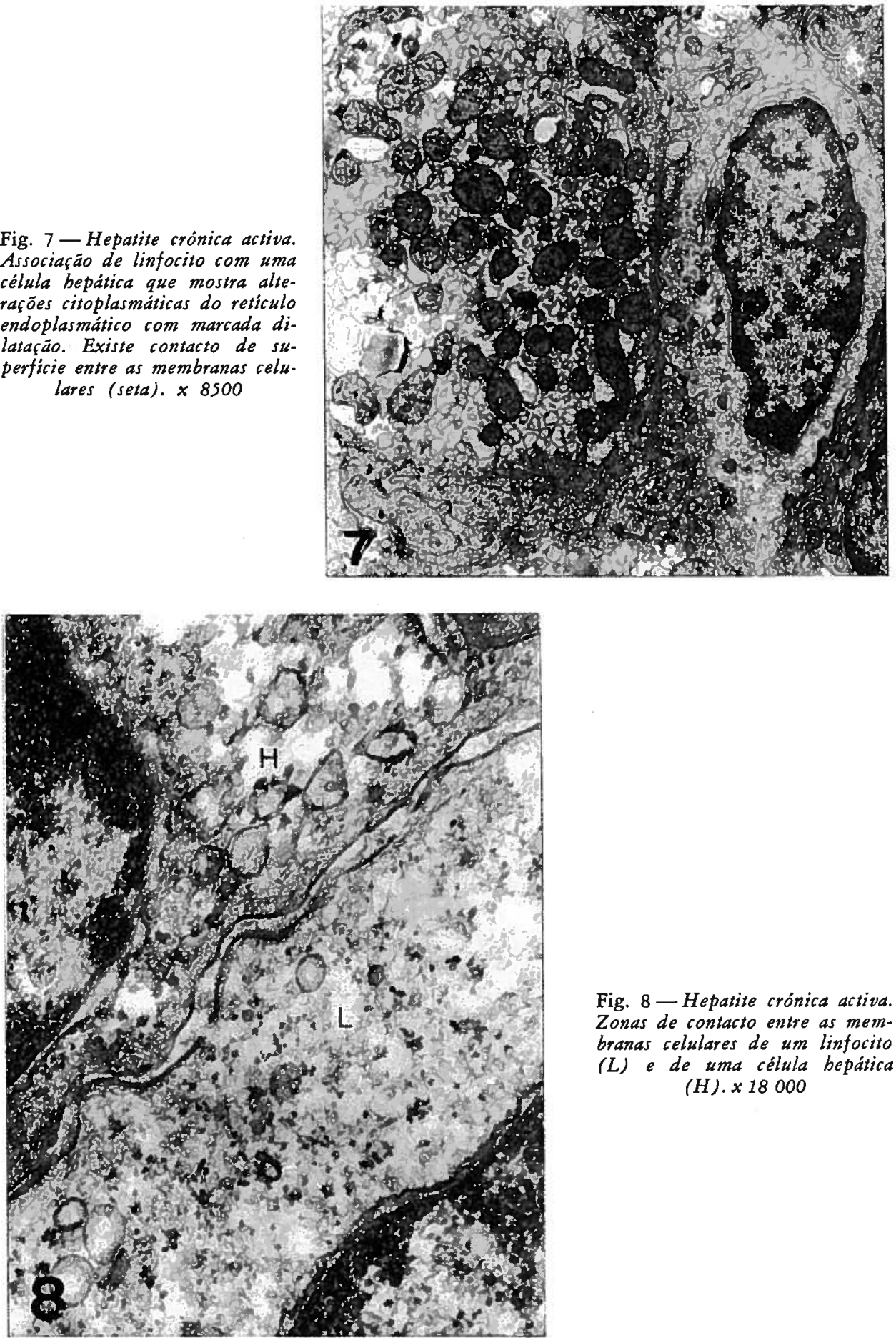

Fig. 8-Hepatite crónica activa. Zonas de contacto entre as membranas celulares de um linfocito (L) e de uma célula bepática (H). $\times 18000$ 
não contrabalançada pela entrada de iões sódio, fenómeno devido à perda dos mecanismos normais de transporte iónico. A célula lisada é eliminada para o compartimento vascular, e, em geral, fagocitada por células macrofágicas.

O cálcio, com desigual distribuição intracelular, acumula-se sobretudo nas mitocôndrias. Em virtude dos desiquilíbrios iónicos nos compartimentos intra- e extra-celulares, libertar-se-ia para o citoplasma, despertando movimentos de membranas que originariam a formação de vacúolos autofágicos e, ulteriormente, de corpos residuais. Igualmente, ao nível das próprias mitocôndrias, ocorreria a activação de fosfolipases que, actuando sobre a sua membrana interna, conduziriam à perda da integridade do organelo.

Quanto às formas evolutivas ou crónicas, o interesse dos investigadores tem-se centrado predominantemente nas técnicas imunológicas, no sentido da compreensão dos mecanismos de persistência e agravamento da doença hepática. Da morfologia tem-se colhido um contributo muito importante na definição dos quadros em que se divide a hepatite crónica, base da classificação actualmente adoptada.

Em trabalho recente, Kawanishi descreve a associação morfológica de linfocitos com hepatocitos, com inter-relações estruturais ao nivel das membranas celulares respectivas (Kawanishi 1977). Em material que estudámos, referente a doentes com hepatite crónica activa, observámos, também, contactos intimos de agregados de pequenos lintocitos com células hepáticas: contactos de superfície, invaginaçōes, penetrações e fusão das membranas citoplasmáticas (Soares s. d.). $\bar{E}$ conhecido, in vitro, o alto grau de especificidade de linfocitos imunes para a lise de células-alvo (Gerottini e Brunner 1974). A associação morfológica de agregados de linfocitos com hepatocitos, na hepatite crónica activa, seria compatível com mecanismos imunológicos mediados por células, e responsáveis pela evolução crónica da doença. Contudo, serão necessárias observações subsequentes para confirmar, efectivamente, se se trata da manifestação estrutural de uma reaç̧ão imunológica, com intervenção de células mediadoras ou efectoras de citotoxicidade, dirigida contra a célula hepática, e responsável pela cronicidade da afecção.

\section{SUMMARY}

In the present paper the contribution of transmission electron microscopy toward a better understanding of the fundamental aspects of the pathology, pathogenesis and etiology of hepatitis B is emphasized.

The main hepatic cell organelle changes occurrying during the course of acute and chronic hepatitis are described and correlated with the hepatic function disturbances

The morphological features of hepatitis B virus antigenic components are briefly described as well as their intra-cellular location and their occurence in the different forms of $\mathrm{HBsAg}$-associated liver disease.

The cellular pathogenesis of the hepatic cell changes in acute hepatitis is discussed. The possibility that the morphological association between lymphocytes and hepatocytes could be related to the immunological mechanism responsible for the chronic evolution of the disease is suggested. 


\section{BIBLIOGRAFIA}

ALMEIDA JB, WATERSON AP: Hepatitis B antigen. An incomplet history. Am J Med Sci 270: 105, 1975.

GERBER MA, SCHAFFNER F, PARONETTO F: Immuno-electron microscopy of hepatitis B antigen in liver. Proc Soc Exp Biol Med 140: 1334, 1972.

GERBER MA, HDJUYANNIS S, VERNACE S, VISSOULIS C: Incidence and nature of cytoplasmic hepatitis B antigen in hepatocytes. Lab Invest 32: 251, 1975.

GEROTTINI JC, BRUNNER KT: Cell-mediated cytotoxicity, allograft rejection and tumor immunity. Adv Immunol 18: 67, 1974.

JEZEQUEL AM, STEINER JW: Electron microscopy of liver biopsies and of transmissible agents from hepatitis patients. Tscbr Gastroenterologie Suppt. 106: 3, 1967.

JOKELAINEN PT, KROHN K, PRINCE AM, FINLAYSON NDC: Electron microscopic observations on virus-like particles associated with SH antigen. I Virol 6: 685, 1970.

KAWANISHI: Morphologic association of lymphocytes with hepatocytes in chronic liver disease. Arch Pathol Lab Med 101: 286, 1977.

MARSELLA RC: A comparative analysis of selected biological markers in the differentiation of Herpesvirus hominis types 1 and 2. Thesis University of Maryland, Baltimore. p. 203. 1972.

RUEBNER BH, SLUSSER RJ: Hepatocytes and sinusoidal lining cells in viral hepatitis. An electron microscopic study. Arch Patbol 86: 1, 1968.

SCHAFFNER F: The structural basis of altered hepatic function in viral hepatitis. Am $J$ Med 49: $658,1970$.

SCOTTO JM, STRALIN HG: Relationship between nuclear bodies and intranuclear invaginations in parenchymal liver cells of patients with viral hepatitis. $J$ Microst Biol Cel 25: 233, 1976.

SOARES JO, MOURA MC: Aspectos ultra-estruturais da hepatite aguda por vírus. I Médico 88: $401,1977$.

SOARES JO, MOURA MC: Nuclear bodies in the hepatic parenchymal cells in acute viral hepatitis. Experientia 31: 1210, 1975.

SOARES, JO: Observações não publicadas.

TRUMP BF, KIM KM, ISERI CA: Cellular pathophysiology of hepatitis. Am $J$ Clin Pathol 65: 828, 1976.

WILLIS EJ: Acute infective hepatitis. Arch Patbol 86: 184, 1968.

WOOLF IL, WILLIAMS R: Significance of persistent $\mathrm{HB}_{\mathrm{s}}$ antigenaemia. Brit Med J 2: 807, 1976.

Pedido de Separatas: Jorge de Oliveira Soares

Unidade de Microscopia Electrónica

Faculdade de Medicina de Lisboa

Lisboa 